\title{
QUEEN'S
UNIVERSITY
BELFAST
}

\section{Capturing challenges and trade-offs in healthcare work using the pressures diagram: An ethnographic study}

Sanford, N., Lavelle, M., Markiewicz, O., Reedy, G., Rafferty, A. M., Darzi, A., \& Anderson, J. E. (2022).

Capturing challenges and trade-offs in healthcare work using the pressures diagram: An ethnographic study. Applied Ergonomics, 101, [103688]. https://doi.org/10.1016/j.apergo.2022.103688

Published in:

Applied Ergonomics

Document Version:

Publisher's PDF, also known as Version of record

Queen's University Belfast - Research Portal:

Link to publication record in Queen's University Belfast Research Portal

Publisher rights

(C) 2022 The Authors.

This is an open access article published under a Creative Commons Attribution License (https://creativecommons.org/licenses/by/4.0/), which permits unrestricted use, distribution and reproduction in any medium, provided the author and source are cited.

\section{General rights}

Copyright for the publications made accessible via the Queen's University Belfast Research Portal is retained by the author(s) and / or other copyright owners and it is a condition of accessing these publications that users recognise and abide by the legal requirements associated with these rights.

Take down policy

The Research Portal is Queen's institutional repository that provides access to Queen's research output. Every effort has been made to ensure that content in the Research Portal does not infringe any person's rights, or applicable UK laws. If you discover content in the Research Portal that you believe breaches copyright or violates any law, please contact openaccess@qub.ac.uk. 


\title{
Capturing challenges and trade-offs in healthcare work using the pressures diagram: An ethnographic study
}

\author{
Natalie Sanford ${ }^{\mathrm{a}, *}$, Mary Lavelle ${ }^{\mathrm{b}, \mathrm{c}}$, Ola Markiewicz ${ }^{\mathrm{c}}$, Gabriel Reedy ${ }^{\mathrm{d}}$, Anne Marie Rafferty ${ }^{\mathrm{a}}$, \\ Ara Darzi $^{c}$, Janet E. Anderson ${ }^{e}$ \\ ${ }^{\text {a }}$ The Florence Nightingale Faculty of Nursing, Midwifery and Palliative Care King's College London, UK \\ b School of Psychology, Queen's University Belfast, UK \\ ${ }^{\mathrm{c}}$ NIHR Patient Safety and Translational Research Centre, Imperial College London, UK \\ d Centre for Education, Faculty of Life Sciences and Medicine, King's College London, UK \\ ${ }^{\text {e }}$ School of Health Science, City University of London, UK
}

\section{A R T I C L E I N F O}

\section{Keywords:}

Resilient healthcare

Human factors

Healthcare safety

\begin{abstract}
A B S T R A C T
Healthcare workers must balance competing priorities to deliver high-quality patient care. Rasmussen's Dynamic Safety Model proposed three factors that organisations must balance to maintain acceptable performance, but there has been little empirical exploration of these ideas, and little is known about the risk trade-offs workers make in practice. The aim of this study was to investigate the different pressures that healthcare workers experience, what risk trade-off decisions they make in response to pressures, and to analyse the implications for quality and safety. The study involved $88.5 \mathrm{~h}$ of ethnographic observations at a large, teaching hospital in central London. The analysis revealed five distinct categories of hospital pressures faced by healthcare workers: efficiency, organisational, workload, personal, and quality and safety pressures. Workers most often traded-off workload, personal, and quality and safety pressures to accommodate system-level priorities. The Pressures Diagram was developed to visualise risk trade-offs and prioritising decisions and to facilitate communication about these aspects of healthcare work.
\end{abstract}

\section{Introduction}

Healthcare workers and healthcare organisations encounter many pressures in everyday clinical work, for example, managing acutely unwell patients and maintaining the quality and safety of care with reduced staffing, fewer resources, and changing organisational priorities (Braithwaite et al., 2015; Kapur et al., 2016; Reader et al., 2018). Although pressure at work is a commonly understood experience, it is not often articulated or defined. In this paper we define pressure as any aspect of the internal or external organisational context that creates emotional stress, increases the tempo of work, or increases the difficulty of work thus requiring more mental or physical effort. Clinicians must balance competing priorities and a pressured environment adds significantly to the difficulty of doing so. Elements to be considered when prioritising include what is best for the patient and family, maintaining best practice, and what is acceptable to the organisation, as well as meeting personal needs such as maintaining work-life balance and avoiding burn-out (Farid et al., 2020; Hall et al., 2016; Reader et al., 2018). These priorities are often at odds with one another, necessitating that healthcare workers adapt flexibly so that work goals can still be met. This means that workers must make difficult decisions about how to manage risk trade-offs (Braithwaite et al., 2015; Reader et al., 2018).

In human factors and naturalistic decision-making research, the conceptualisation of risk trade-offs has centred around forms of costbenefit analysis (Bertsimas et al., 2012; Hollnagel, 2009; Pauker and Kassirer, 1975; Reader et al., 2018). In addition to traditional resource cost-benefit analysis, researchers have examined other components that are at odds with one another like the trade-off between efficiency and thoroughness (Hollnagel, 2009) and efficiency and fairness (Bertsimas et al., 2012). Others, such as Reader et al. (2018), have accounted for considerations like experience and organisational norms that may drive decision-making. We adopt a broad definition of risk trade-offs to enable us to consider how different healthcare pressures might be prioritised when they occur. Therefore, in this paper, a risk trade-off is defined as

\footnotetext{
* Corresponding author. Florence Nightingale Faculty of Nursing, Midwifery \& Palliative Care King's College London, James Clerk Maxwell Building 1.3257 Waterloo Road, London, SE1 8WA, UK.

E-mail address: natalie.sanford@kcl.ac.uk (N. Sanford).
} 
any decision made during which a decision-maker compromises one or more factors when considering two or more desirable but competing factors. Risk trade-offs occur when decision-makers must consider what outcome to prioritise when it is not possible to maximise all outcomes (Hollnagel, 2009; Jeffs et al., 2009; Reader et al., 2018; Slovic et al., 2004).

Although previous studies have examined work pressures in isolation, few studies consider the relationship between them. The aims of this study were to assess the interplay of a variety of competing pressures, to analyse risk trade-offs when multiple pressures are present, and to consider the implications of these decisions at the individual and system levels.

\subsection{Interrelated pressures}

So far empirical research to understand pressures and trade-offs in healthcare has focused on one or two pressures in isolation. However, the occurrence of multiple, simultaneous pressures can impinge on clinical work, decision-making, and the organisation (Farid et al., 2020; Hollnagel et al., 2014; Miller and Xiao, 2006; Reader et al., 2018; Sujan et al., 2015). One existing theoretical model that conceptualises the interplay of competing pressures faced by a system is Rasmussen's dynamic safety model, which proposes three factors that organisations must balance to maintain acceptable performance - safety, economic efficiency, and acceptable workload (Cook and Rasmussen, 2005; Rasmussen, 1997).

Rasmussen's model proposes that there are dynamic pressures that operate on organisations to shift their operations towards boundaries of unacceptable performance. Organisations that are unable to counter these pressures effectively are at risk of financial failure, accidents, and reduced quality (Cook and Rasmussen, 2005; Rasmussen, 1997). Rasmussen (1997) suggests that making the boundaries and the operating point more visible could improve safety and enhance the ability of the organisation to cope when nearing the boundaries. He also argues that compensatory adaptations to challenges have implications for the boundaries themselves which may be unforeseen at the time that the adaptation takes place.

Despite proposing a means to understand how pressures and risks interact at the organisational level, Rasmussen's model has received relatively little empirical investigation, meaning that the pressures and risks are not well described or understood in practice (Ellis et al., 2019; Le Coze, 2015; Vicente and Christoffersen, 2006). Although it is well recognised that decisions made in response to situational demands can lead to incremental changes in practice that result in the organisation drifting towards operating in risky conditions, few empirical studies capture these changes and drifts. As Rasmussen suggested, making these processes transparent is the first step towards understanding the organisational dynamics that underpin high-risk operations and reducing the risks of pressured environments. However, the Rasmussen (1997) model was published over two decades ago and is a high-level representation not designed to capture the pressures impinging on contemporary healthcare organisations. It is therefore timely to revisit the concepts and model using empirical data.

This research seeks to illuminate how the pressures of the healthcare environment are navigated by clinicians during their everyday work. Clinicians are adept at balancing competing priorities when making clinical decisions. Understanding more about how they make equally complex organisational decisions provides insight into perceived organisational priorities and can inform the development of interventions to improve organisational quality, safety, and efficiency.

\subsection{Clinical risk trade-offs versus risk trade-offs in response to pressure}

We have distinguised betweern pressure risk trade-offs and clinical risk trade-offs, such as regular patient care plan decisions or even rapid patient deterioration scenarios like stroke or cardiac arrest. This is because algorithmic procedures and factors to consider when making clinical risk trade-off decisions are better defined and in some cases wellrehearsed (Amalberti and Vincent, 2020). Clinical decision-making tools are embraced in healthcare and have been inspired by other industries like engineering and aviation (Kapur et al., 2016; Reader et al., 2018). Some of these tools, like surgical checklists or cardiac arrest algorithms, have had success at decreasing variability and mitigating risk when establishing the best course of action in a clinical scenario (Kapur et al., 2016; Reader et al., 2018). Conversely, pressure and sources of pressure experienced by healthcare workers are variable and unpredictable requiring workers to improvise responses and decisions. The same combination of pressures is unlikely to occur in the same way more than once, whereas patient care and deterioration are more regular and patterned. Risk trade-offs in response to pressure relate to the organisation of care and potentially affect the care of many patients. Factors such as how these pressures and trade-offs impact quality and safety, working conditions, healthcare worker well-being, patient and clinician satisfaction, and staff retention must be considered to ensure the sustainability of healthcare systems. Studying these decisions requires empirically and theoretically informed tools but such tools do not yet exist.

\section{Research aims}

The aims of this study were:

1. To identify and categorise the types of pressures that healthcare workers experience

2. To understand what risk trade-off decisions are made in response to pressures

3. To analyse the implications of risk trade-offs for the quality and safety of care

\section{Methods}

This paper reports an in-depth analysis of ethnographic observations of routine working in hospital teams. This dataset was recorded as part of a larger study of adaptive teamwork in healthcare, which had the aim of identifying misalignments between demand and capacity; identifying mechanisms of adaptation to challenges; and uncovering sources of adaptive capacity using a conceptual model of organisational resilience (Anderson et al., 2016). The study was conducted in a hospital setting with teams that differed according to goals, membership, longevity, and type of tasks. The study involved $88.5 \mathrm{~h}$ of ethnographic observations in a large, teaching hospital in central London.

\subsection{Setting and participants}

The study employed purposive sampling of five diverse clinical care environments: two surgical wards, an older adult ward, a critical care unit, and the Acute Assessment Unit (AAU-a temporary ward to expedite patient flow from the emergency department to the in-patient wards). The study had ethical approval (REC REF:18/WA/0218) and formal approval from the hospital management. In each of the participating ward areas the lead doctor(s) (e.g., consultant) and the lead nurse (s) (e.g., ward matron) were provided with information about the study in the form of a verbal presentation and written study information sheets. For a ward to participate in the study, written informed consent was required from all clinical leads (doctors and nurses) on that ward. Staff leads also provided their consent for researchers to shadow them during their routine work. In total, 36 healthcare staff provided written informed consent to participate, enabling data collection of routine work across five ward areas. 


\subsection{Data collection}

The research team consisted of clinicians and non-clinicians from varied backgrounds, including social science, psychology, human factors, nursing, medicine, and education. Non-participant ethnographic observations were conducted by two trained researchers (ML and OM) over a six-month period between October 2018 and March 2019. In all, $88.5 \mathrm{~h}$ of observations were completed across the participating clinical areas. Researchers observed ward rounds, medication rounds, and general ward activities, as well as coordinating events like handovers, board rounds, multi-disciplinary team (MDT) meetings, and bed meetings. These events were observed in the locations in which they naturally occurred, and so were not necessarily confined to the ward area. Observers also shadowed ward leads from participating wards to coordinating events involving representatives from multiple wards (e.g., bed meetings). In-depth ethnographic field notes were transcribed and uploaded into NVivo 12 for storage, organisation, and analysis on a password protected computer. Identifying information for all participants was removed.

\subsection{Data analysis}

Analysis of the ethnographic observations was undertaken between July and October 2020. An inductive approach to thematic analysis consisted of two phases. In phase one, after initial data immersion, coding was completed in NVivo 12 by author NS. The data were coded using the larger theme of "pressures." Pressure was defined as an aspect of the organisational context that resulted in emotional stress, increased tempo of work, or increased difficulty of work. Instances of pressure were initially identified in the transcripts based on descriptions of the mood of the ward; conversations among staff members about strain, stress, or challenges; increased pace of work; observations of tasks being neglected or things not being followed-up; and discussions among staff members about trade-offs. After initial coding, further analysis identified five sub-themes distinguishing between different types of pressures: efficiency, organisational, personal, workload, and quality and safety pressures (See Table 1). These themes were discussed and iterated with the larger research team during team meetings to ensure conceptual agreement was present throughout the analysis process. The team met regularly throughout the data analysis process to agree and interpret results, reviewing the data and the analysis process, and sense-checking the analysis framework. Two members of the research team were nurses and one member was a physician. In addition to conversations with staff during the ethnography to clarify observed events, the team members' familiarity with the clinical environment and its processes were also essential to understanding and identifying the phenomena of interest during the analysis process. After these themes were finalised, events following the pressure were coded to identify what pressure trade-off decisions were made. When a pressure occurred, this pressure was coded as 'traded-off' if the pressure was neglected, ignored, or compromised. The pressure was coded as 'managed' if the pressure was addressed or prioritised. These trade-off decisions were identified based on observations of work prioritisation and conversations among staff members surrounding the management of competing priorities, tasks, and needs. Clinical trade-offs, for instance, weighing up the pros and cons of a single patient's treatment options, were excluded from the analysis. At the completion of the first phase of data analysis, there were three parent codes: "pressures," "trade-offs," and "pressures managed," each with five sub codes (one for each identified pressure type) for a total of three parent codes and 15 sub-codes.

In phase two of data analysis, the relationship between pressures and trade-offs was explored. A paired, matrix coding query was run in NVivo 12 to identify segments of text which were coded for both a pressure and a corresponding trade-off. The matrix coding query function is similar to a search function and identifies text coded as both a pressure and a trade-off. The number of trade-offs for each pressure was quantified and compared to the total number of times each pressure occurred. This allowed us to determine the percentage of the time that each pressure was traded-off to understand more about which pressures, if any, were more likely to be traded-off than others.

\section{Results}

The analysis revealed five distinct categories of hospital pressures faced by healthcare workers: efficiency, organisational, workload, personal, and quality and safety pressures (see Table 1).

Table 1 displays the number of times each pressure was observed, the total number of pressures observed $(n=246)$, and the percentage of the total pressures that each pressure category accounted for. Each pressure occurred a similar percentage of the time, apart from personal pressures, which were observed less frequently than the other four pressures. Additionally, Table 1 displays how many times each pressure was

Table 1

Description of pressures, number of times observed, percentage of all pressures observed, number of times risk traded off, percentage traded off, and observed risk trade-off examples.

\begin{tabular}{|c|c|c|c|c|c|c|}
\hline Pressure & Description & $\mathrm{n}$ & $\begin{array}{l}\text { Percentage of All } \\
\text { Pressure } \\
\text { Occurrences }(\%)\end{array}$ & $\begin{array}{l}\text { Number of } \\
\text { Risk Trade- } \\
\text { offs (n) }\end{array}$ & $\begin{array}{l}\text { Percentage } \\
\text { Traded Off (\%) }\end{array}$ & Risk Trade-off Example from Observations \\
\hline Efficiency & Maintaining time and cost efficiency & 56 & 23 & 8 & 14.3 & $\begin{array}{l}\text { The doctor spends extra time consoling a delirious } \\
\text { patient, which sets the doctor behind schedule on } \\
\text { her ward rounds }\end{array}$ \\
\hline Organisational & $\begin{array}{l}\text { Having access to enough beds and } \\
\text { qualified individuals to provide care to } \\
\text { patients }\end{array}$ & 48 & 20 & 5 & 10.4 & $\begin{array}{l}\text { The patient is ready for discharge and beds in the } \\
\text { hospital are scarce. The patient needs a } \\
\text { Zimmerframe before they are discharged, but the } \\
\text { physiotherapist has already left the hospital. Rather } \\
\text { than calling the physiotherapist at home, the team } \\
\text { delays patient discharge until Monday }\end{array}$ \\
\hline $\begin{array}{l}\text { Quality and } \\
\text { Safety }\end{array}$ & $\begin{array}{l}\text { Mitigating risk and harm, considering } \\
\text { patient experience, balancing the needs } \\
\text { of multiple patients, and delivering } \\
\text { timely and effective care }\end{array}$ & 62 & 25 & 30 & 48.4 & $\begin{array}{l}\text { The nurse draws up multiple patients' medications } \\
\text { at one time and does not label them }\end{array}$ \\
\hline Workload & $\begin{array}{l}\text { Ensuring that one's workload is } \\
\text { manageable and within the range of } \\
\text { what one is willing to contribute } \\
\text { without causing harm to the worker }\end{array}$ & 61 & 25 & 47 & 77.0 & $\begin{array}{l}\text { The surgical team covers their usual patient list as } \\
\text { well as another team's patient list due to low } \\
\text { staffing, making ward rounds untenable }\end{array}$ \\
\hline Personal & $\begin{array}{l}\text { Meeting personal needs, like taking } \\
\text { breaks, leaving work on time, eating, } \\
\text { and using the restroom }\end{array}$ & 19 & 8 & 14 & 73.7 & $\begin{array}{l}\text { The manager stays } 2 \mathrm{~h} \text { beyond their rostered shift to } \\
\text { help on the busy ward }\end{array}$ \\
\hline Total & - & 246 & 100 & 104 & 42.3 & - \\
\hline
\end{tabular}


traded-off and that data expressed as a percentage. Hospital workers were challenged with maintaining acceptable performance when pressures arose, especially if multiple pressures occurred simultaneously, requiring workers to make risk trade-offs. Trade-offs occurred when a pressure was present but was compromised by the worker or team to address another competing pressure. The pressure traded-off the most frequently was workload, which was traded-off $77.0 \%$ of the time. Furthermore, although personal pressures were observed the least frequently, when they were observed, they were traded-off the second highest percentage of the time compared to the other pressures $(n=14$, $73.7 \%$ ). Quality and safety pressures were traded-off $48.4 \%$ of the time that the pressure was observed. Efficiency, organisational, and patient pressures were rarely traded-off when they were observed, highlighting that these may be prioritised by healthcare teams more than the other pressures when determining risk trade-offs. The next section will present the Pressures Diagram, which is a visual tool to illustrate these pressures and trade-offs.

\subsection{Development of the pressures diagram}

Based on our empirical findings, we propose an extension and reconceptualization of Rasmussen's dynamic safety model. The diagram is a visual model to communicate the trade-offs and prioritising decisions that healthcare workers must balance in everyday clinical work. It enables visualisation of the interplay of all the competing priorities we observed in this study.

The diagram (Fig. 1) can be used to consider all the pressures that impinge on workers in a given situation and to discuss how prioritising decisions affect performance. It shows the five pressures and the notional operating point for a given scenario. The five pressures overlap in a Venn diagram, with one circle for each type of observed pressure. The notional operating point, indicated by a star, shows which pressures are prioritised by the individual, team, or organisation, and therefore which pressures are traded-off in each situation. If the operating point falls within the pressure's circle of the Venn diagram, that pressure has been prioritised. If the operating point falls within an area of overlap of multiple pressure circles, those multiple pressures have all been prioritised. If the operating point does not fall within a pressure, that pressure has been traded-off. To use the diagram to illustrate specific scenarios, pressures can be removed from the diagram if not present or shifted in their orientation to one another around the diagram to allow for all combinations of overlap. The zone at the centre of the diagram, indicated by the small circle, is the point where all the pressures overlap. In this zone, all pressures that have arisen are managed to an acceptable level and no risk trade-offs have been made. In times of immense pressure, when all five pressures are present, this level of performance is conceptualised as being difficult (if not impossible) to achieve.

Deciding whether a pressure has been prioritised or traded-off is

\section{Efficiency}

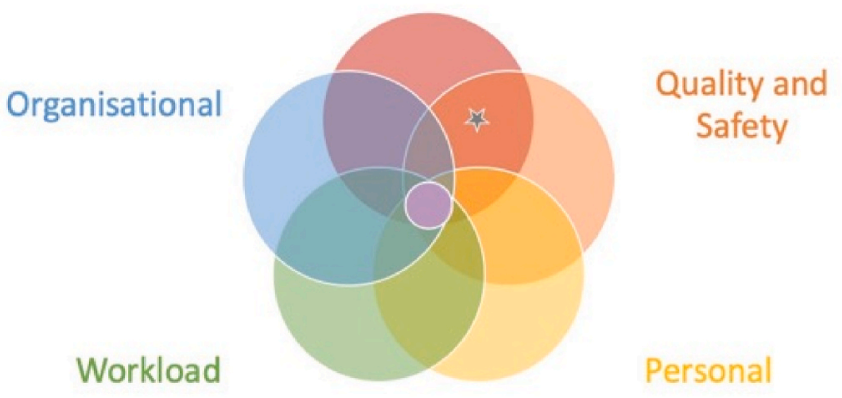

Fig. 1. The pressures diagram. more or less difficult depending on the situation in question. In some cases, pressures will have pre-agreed boundaries of acceptable performance making it clear when they have been traded-off (as in Rasmussen's (1997) model) and others are nuanced and determined on a case-by-case basis. As such, making these determinations is complex and is also at the discretion of the user of the model. Unlike Rasmussen's (1997) model, the Pressures Diagram is intended to be binary for each pressure, such that the exact location of the notional operating point within each pressure circle is not significant other than that it is placed within one of the discrete intersections. While this determination is up to the diagram user, which does entail a degree of subjectivity, the Pressures Diagram contributes a reflective, conversational tool to conceptualise the multitude of pressures faced by workers in complex systems. It can be used to illustrate challenges and trade-offs in multiple settings, for research, educational, or conversational purposes. It is intentionally written in accessible, non-discipline specific terminology to allow for cross-discipline use.

\subsection{Observed clinical examples}

In this section, the model will be used to illustrate scenarios from our observations. The first example (Fig. 2) illustrates a time when all pressures occurred at once; the second (Fig. 3) showcases an instance when the healthcare team had fewer pressures arise at once, allowing them to work without any trade-offs; and the third example (Fig. 4) highlights a time when fewer pressures arose, but pressures were still traded-off.

In the scenario illustrated in Fig. 2, a ward was challenged with high acuity patients. Given the acuity of the patients, the number of staff caring for the patients was not sufficient, but additional staff were not recruited, and beds were not blocked or closed for new admissions (organisational pressure, quality and safety pressure). Due to the increased strain on the team, the ward manager (WM) temporarily disregarded their managerial tasks to help by delivering medications for the nurses, checking on patients, cleaning bays, and delivering meal trays. This meant that ward work was completed on time (efficiency pressure), but the WM had to stay late to complete outstanding management tasks and did not take a lunch break (workload pressure, personal pressure). The WM faced all five pressures simultaneously and traded-off workload and personal pressures, prioritising the other three.

In another instance, illustrated in Fig. 3, the admitting team faced four pressure types during a patient admission. A female patient needed to be admitted so she could be cared for by the team (quality and safety pressure), but there was an organisation-wide lack of beds and the only remaining bed on the ward was in a 'male' bay (organisational and quality and safety pressures). One of the metrics the ward must report is whether they have any 'gender breaches' when placing patients. A 'gender

\section{Efficiency}

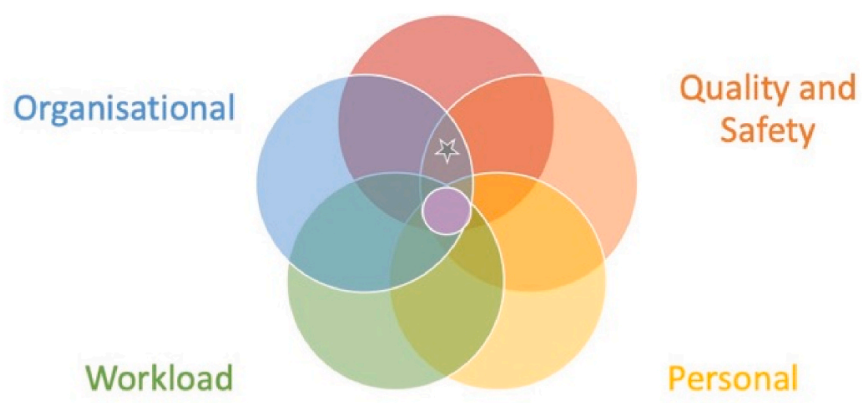

Fig. 2. Pressures diagram for scenario 1- ward manager works longer than rostered shift. 


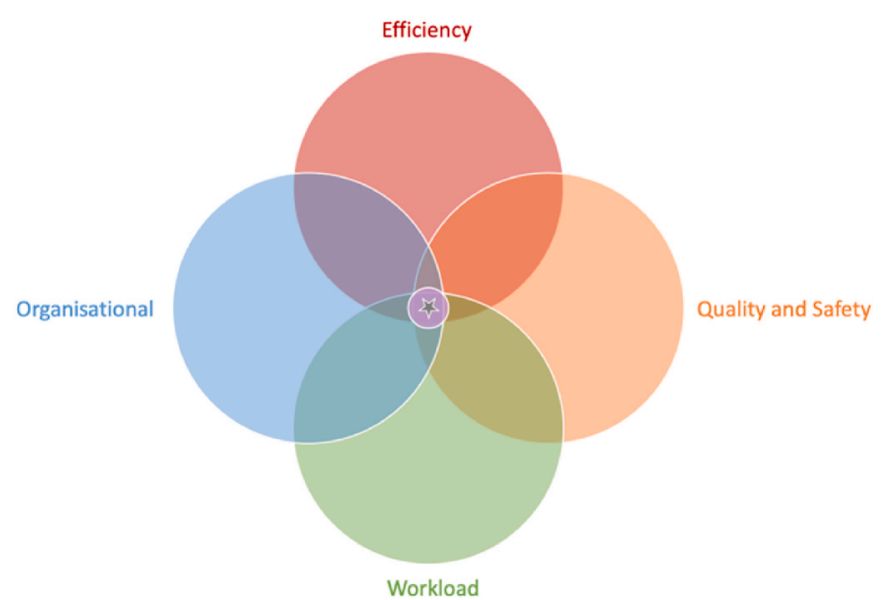

Fig. 3. Pressures diagram for scenario 2- temporary gender breach on admission.

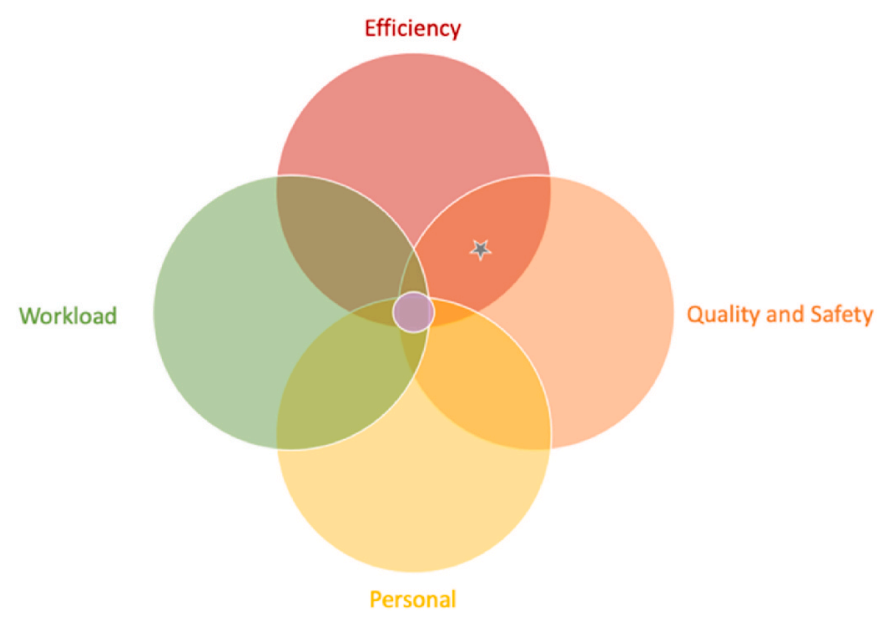

Fig. 4. Pressures diagram for scenario 3- doctors stay late to complete tasks.

breach' occurs when a male patient and female patient are roommates in a bay. It is only required that such a breach be reported if it occurs for longer than $6 \mathrm{~h}$ (quality and safety pressure). The team was keen to care for the new patient as quickly as possible without any lags in care (efficiency and quality and safety pressures) so they worked around the mismatch by temporarily admitting the patient to the male bay, knowing that they would be able to move her to the bed of a soon-to-be discharged female patient within the 6-h timeframe. The adaptation created additional work for the staff as the bays had to be cleaned twice and the patients shuffled around creatively (workload pressure), but the work was accomplished without overstretching the team. The adaptation temporarily impinged on quality and safety metrics as well as perhaps the patient's experience of care. However, this took place without surpassing the agreed acceptable timeframe for the breach and the more pressing quality and safety need (prompt care) was achieved for the patient. While the care delivered was perhaps not 'ideal,' the team adapted to the pressures without any trade-offs that breached preset constraints of acceptable care.

In another scenario, seen in Fig. 4, two first-year resident doctors discussed how they were working beyond their rostered hours. In this case, the consultant (attending physician) completed a second round at 5:00pm to check on the team's patients (quality and safety pressure). This in turn created more work for the junior doctors on the team. The doctors described that although they were only rostered until 5:30pm, that it was typical to stay at the hospital until 7:00pm or later due to the additional work generated by this additional daily round (workload pressure, personal pressure). The culture on this surgical team was to complete these jobs immediately rather than passing them off to the night team or attending to them the next day (efficiency pressure). In this case, the doctors traded-off personal and workload pressures to manage the quality and safety and efficiency pressures. This is another instance in the observations when a healthcare worker compromised their personal needs to accommodate other priorities.

\section{Discussion}

Pressures are a ubiquitous feature of healthcare work that impede workers' ability to complete work-as-imagined in procedures and policies and necessitate risk trade-offs. This study focused on identifying the different types of pressures to better capture the reality of complex systems and trade-offs. Understanding which pressures are traded-off and which are prioritised could help us to understand how to best support healthcare workers' adaptations and decision-making as well as to help us understand where to target interventions. Our analysis shows that healthcare workers prioritise system-level pressures like efficiency and organisational pressures. Workers sacrificed personal needs, workload, and quality and safety in their risk trade-offs to manage these organisational priorities. Indeed, $73.7 \%$ of personal pressures, $77 \%$ of workload pressures and $48.4 \%$ of quality and safety pressures were traded off. Conversely, only $10.4 \%$ of organisational pressures and $14.3 \%$ of efficiency pressures were traded off. All pressures were observed with similar frequency, apart from personal pressures, which were observed less frequently. Personal pressures may have been observed less frequently than the other pressures because they are experienced internally and are therefore less visible to observation. For instance, organisational pressures, such as bed availability, may be explicitly discussed by team members, but a team member might not verbalise when they have personal needs, like needing a break or leaving work on time. Despite this, interestingly, in situations when all pressures were present, workers always traded off workload and personal pressures to meet other demands. These findings suggest that workers prioritise system-level challenges when determining risk trade-offs.

Our data and resulting diagram illustrate the complexity of healthcare work in which multiple pressures occur and competing priorities must be resolved. Healthcare workers often sacrificed their personal needs and tolerated increased workloads to prioritise other aspects of the work, raising concerns about the long-term impact on workers' health and workforce sustainability. Recent studies have drawn attention to the number of disruptions faced by healthcare workers, have highlighted the prevalence of burnout, have linked burnout with decreased patient safety, and have emphasised the importance of combatting burnout for the long-term sustainability of the healthcare system (Bakhamis et al., 2019; Hall et al., 2016; Sinnott et al., 2022; Tawfik et al., 2019; Thorpe, 2020). The onus usually falls on the individual to combat these challenges (Montgomery, 2014). Interventions like encouraging workers to take breaks and implementing mindfulness, yoga, and mental health services, among others, have been suggested as a means of addressing burnout and dissatisfaction (Cocchiara et al., 2019; Goodman and Schorling, 2012; Ofei-Dodoo et al., 2020; Rogers et al., 2004; Stefancyk, 2009). A further concern is the chronic shortage of nursing staff and staff turnover and the consequences these chronic problems have for the sustainability of health systems. This is especially true considering the Covid-19 pandemic, which has exacerbated these existing problems (Rangachari \& J, 2020). It is clear the pandemic has amplified issues of burnout (House of Commons Health and Social Care Committee, 2021) as well as exacting a significant toll on the mental health and well-being of staff (Lamb et al., 2021) during which younger female nurses were found to be most vulnerable. This adds to the burden on the newly qualified workforce and points to the need to identify specific support mechanisms tailored to their needs. In the long-term, problems such as healthcare worker burnout, patient safety, and poor staff retention are multifactorial and require attention on the system 
level as well as the individual level.

We also observed that the quality and safety of care was sometimes sacrificed to meet organisational goals of efficiency and resource provision. The examples we observed resulted in temporary lowering of standards of patient experience and sacrificing quality targets and did not cause visible patient harm. However, the pressures we observed were pervasive and sustained, raising the question of how long a healthcare system can operate in such conditions without causing harm to patients, staff, or both, despite the best intentions of staff. Our study highlights the interconnected pressures that impinge on healthcare work, the dynamic risk trade-offs that individuals and teams make as they navigate the system, and the dangers of a healthcare system under pressure.

Rasmussen's (1997) dynamic model of risk and safety suggests boundaries and gradients that illustrate the complexity of work-as-done and the competing pressures faced by workers as they navigate maintaining acceptable performance. This paper builds on that work by examining these ideas using empirical data from a healthcare setting. It does so by consolidating, modifying, expanding, and further specifying some of the concepts from the dynamic model of risk and safety, and by contributing additional pressure categories which were not featured as constraints or gradients in Rasmussen's (1997) model. The Rasmussen (1997) concept of the three boundaries of operation was extended from three boundaries to five and reimagined to better represent our findings and capture all of the pressures faced in healthcare organisations.

\subsection{Strengths and limitations}

The strength of this work is that the resulting model has been derived directly from empirical research using a theory-driven inductive approach by a diverse research team with clinical experience and academic backgrounds in nursing, medicine, psychology, history, and medical education. The themes were constructed from a large and varied dataset that included multiple team types, settings, professions, and activities. This empirically based research is a significant contribution to theory development. Although Rasmussen's (1997) model provides a useful lens for considering how operators move within three boundaries and how forces might move the operator toward or away from these boundaries, a challenge when applying the model is determining how near or far from the boundaries to place the operating point. In addition to the contribution of new pressures, unlike the Rasmussen (1997) model, the Pressures Diagram does not require that the user appraise the degree to which a pressure was or was not traded-off. Instead, the notional operating point is placed on the Venn Diagram on a pressure circle or intersection, eliminating the need to measure the 'location' of the operating point relative to each boundary. This is a strength of the model.

The Pressures Diagram has multiple, flexible uses. Firstly, in addition to providing insight into specific scenarios, it also enables one to consider how pressures and trade-offs vary over time. For instance, a pressure may be prioritised earlier in a shift to reduce that pressure later in the shift. Dynamic anticipatory and compensatory actions are an essential part of complex work, but these temporal impacts of trade-offs are difficult to capture. Thus, the Pressures Diagram can be used to represent the evolution of pressures and trade-offs to determine patterns over a continuum. Secondly, the non-technical language used in the diagram also enables experts to leverage the perceptions of different stakeholders, who may offer alternative views of the system, pressures, and trade-offs, which facilitates multi-role comparison and identification of disparities. Thirdly, the Pressures Diagram is not prescriptive in its depiction of context. For example, the diagram user could provide a narrative summary in written or in verbal form, as we have in our examples, to explain the situational context. Alternatively, the user could write captions or lists within each circle of the Venn diagram to illustrate each pressure and trade-off. This flexibility enables individual interpretation and preference and means that the diagram can be used in multiple settings and for multiple purposes. Finally, the pressures diagram incorporates pressures from all levels of the organisation. One of the pressures (personal) is on the micro level, one of the pressures (organisational) is on the macro level, and the other three pressures can flexibly represent any level of the organisation. As all elements of the organisation influence and impact the operations on the other levels, we believe this is a strength of the model. Incorporating all system levels in the model more accurately represents complex work than examining each level in isolation and may offer insight into important links between system levels.

A limitation of the study is that it is possible that not all pressures, adaptations, and trade-offs are explicit and visible, so there is the possibility that the categories of pressures and/or the relationship between pressures established within this paper are incomplete. In some cases, it may be difficult to determine if there was a trade-off as benefits of prioritising pressures may occur later in time and not be immediately observable. Additionally, data were collected in one organisation and it is not clear whether the same results would be obtained in a different organisation. Further research could establish whether these themes and patterns are found elsewhere. Additionally, once more data has been collected and understanding of pressures and trade-offs has been improved, targeted interventions to support decision-making should be created.

\section{Conclusions}

In today's healthcare environment different types of pressures necessitate complex trade-offs to resolve competing priorities. Understanding these decisions and their consequences is vital for devising interventions to reduce pressures and support workers in adapting to the pressures. Most pressures were resolved by workers sacrificing personal needs, tolerating increased workload, or accepting temporarily lower quality of care standards, adaptations that have possibly serious consequences for health and workforce sustainability and patient experience. The Pressures Diagram provides a means of conceptualising the interrelatedness of the pressures and can be used for research, educational, and conversational purposes to raise awareness of and make explicit trade off decisions and their consequences.

\section{Funding}

This study was supported by the NIHR Imperial Patient Safety Translational Research Centre [PSTRC-2016-004]. The views expressed are those of the author(s) and not necessarily those of the NIHR or the Department of Health and Social Care. Infrastructure support for this research was also provided by the NIHR Imperial Biomedical Research Centre (BRC).

\section{Declaration of competing interest}

The authors declare that they have no known competing financial interests or personal relationships that could have appeared to influence the work reported in this paper.

\section{References}

Amalberti, R., Vincent, C., 2020, Jan. Managing risk in hazardous conditions: improvisation is not enough. BMJ Qual. Saf. 29 (1), 4-6. https://doi.org/10.1136/ bmjqs-2019-009703.

Anderson, J.E., Ross, A.J., Back, J., Duncan, M., Snell, P., Walsh, K., Jaye, P., 2016. Implementing resilience engineering for healthcare quality improvement using the CARE model: a feasibility study protocol. Pilot Feasibility Stud 2 (61). https://doi. org/10.1186/s40814-016-0103-x.

Bakhamis, L., Paul 3rd, D.P., Smith, H., Coustasse, A., 2019, Jan/Mar. Still an epidemic: the burnout syndrome in hospital registered nurses. Health Care Manag. 38 (1), 3-10. https://doi.org/10.1097/HCM.0000000000000243.

Bertsimas, D., Farias, V.F., Trichakis, N., 2012. On the efficiency-fairness trade-off. Manag. Sci. 58 (12), 2234-2250. https://doi.org/10.1287/mnsc.1120.1549. 
Braithwaite, J., Wears, R.L., Hollnagel, E., 2015, Oct. Resilient health care: turning patient safety on its head. Int. J. Qual. Health Care 27 (5), 418-420. https://doi.org 10.1093/intqhc/mzv063.

Cocchiara, R.A., Peruzzo, M., Mannocci, A., Ottolenghi, L., Villari, P., Polimeni, A., Guerra, F., La Torre, G., 2019, Feb 26. The use of yoga to manage stress and burnout in healthcare workers: a systematic review. J. Clin. Med. 8 (3) https://doi.org/ $10.3390 / \mathrm{jcm} 8030284$.

Cook, R., Rasmussen, J., 2005, Apr. Going solid": a model of system dynamics and consequences for patient safety. Qual. Saf. Health Care 14 (2), 130-134. https://doi. org/10.1136/qshc.2003.009530.

Ellis, L.A., Churruca, K., Clay-Williams, R., Pomare, C., Austin, E.E., Long, J.C., Grødahl, A., Braithwaite, J., 2019. Patterns of resilience: a scoping review and bibliometric analysis of resilient health care. Saf. Sci. 118, 241-257. https://doi.org/ 10.1016/j.ssci.2019.04.044.

Farid, M., Purdy, N., Neumann, W.P., 2020, Aug. Using system dynamics modelling to show the effect of nurse workload on nurses' health and quality of care. Ergonomics 63 (8), 952-964. https://doi.org/10.1080/00140139.2019.1690674.

Goodman, M.J., Schorling, J.B., 2012. A mindfulness course decreases burnout and improves well-being among healthcare providers. Int. J. Psychiatr. Med. 43 (2), 119-128. https://doi.org/10.2190/PM.43.2.b.

Hall, L.H., Johnson, J., Watt, I., Tsipa, A., O'Connor, D.B., 2016. Healthcare Staff Wellbeing, Burnout, and Patient Safety: a Systematic Review. PLoS One 11 (7), e0159015. https://doi.org/10.1371/journal.pone.0159015.

Hollnagel, E., 2009. In: The ETTO Principle: Efficiency-Thoroughness Trade-Off: Why Things that Go Right Sometimes Go Wrong, first ed. CRC Press. https://doi.org/ $10.1201 / 9781315616247$.

Hollnagel, E., Wears, R.L., Braithwaite, J., 2015. From Safety-I to Safety-II: a white paper. The Resilient Health Care Net: Published Simultaneously by the University of Southern Denmark. University of Florida, USA, and Macquarie University, Australia.

Jeffs, L., Tregunno, D., MacMillan, K., Espin, S., 2009. Building clinical and organizational resilience to reconcile safety threats, tensions, and trade-offs: insights from theory and evidence. Healthc. Q. 12. Special Issue.

Kapur, N., Parand, A., Soukup, T., Reader, T., Sevdalis, N., 2016, Jan. Aviation and healthcare: a comparative review with implications for patient safety. JRSM Open 7 (1). https://doi.org/10.1177/2054270415616548, 2054270415616548.

Lamb, D., Gnanapragasam, S., Greenberg, N., Bhundia, R., Carr, E., Hotopf, M., Razavi, R., Raine, R., Dewar, A., Docherty, M., Dorrington, S., Hatch, S.L., WilsonJones, C., Leightley, D., Madan, I., Marlow, S., McMullen, I., Rafferty, A.M., Parsons, M., Wessely, S., 2021. The psychosocial impact of COVID-19 pandemic on 4,378 UK healthcare workers and ancillary staff: initial baseline data from a cohort study collected during the first wave of the pandemic. Occup. Environ. Med. 78 (11), 801-808.

Le Coze, J.C., 2015. Reflecting on Jens Rasmussen's legacy. A strong program for a hard problem. Saf. Sci. 71, 123-141. https://doi.org/10.1016/j.ssci.2014.03.015.
Miller, A., Xiao, Y., 2006. Multi-level strategies to achieve resilience for an organisation operating at capacity: a case study at a trauma centre. Cognit. Technol. Work 9 (2), 51-66. https://doi.org/10.1007/s10111-006-0041-0.

Montgomery, A., 2014. The inevitability of physician burnout: implications for interventions. Burnout Res. 1 (1), 50-56. https://doi.org/10.1016/j. burn.2014.04.002.

Ofei-Dodoo, S., Cleland-Leighton, A., Nilsen, K., Cloward, J.L., Casey, E., 2020, Aug. Impact of a mindfulness-based, workplace group yoga intervention on burnout, selfcare, and compassion in health care professionals: a pilot study. J. Occup. Environ. Med. 62 (8), 581-587. https://doi.org/10.1097/JOM.0000000000001892.

Pauker, S.G., Kassirer, J.P., 1975. Therapeutic decision making: a cost-benefit analysis. N. Engl. J. Med. 293 (5), 229-234. https://doi.org/10.1056/ nejm197507312930505.

Rangachari, P., J, L.W., 2020, Jun 15. Preserving organizational resilience, patient safety, and staff retention during COVID-19 requires a holistic consideration of the psychological safety of healthcare workers. Int. J. Environ. Res. Publ. Health 17 (12). https://doi.org/10.3390/ijerph17124267.

Rasmussen, J., 1997. Risk management in a dynamic society: a modelling problem. Saf. Sci. 27 (2-3), 183-213.

Reader, T.W., Reddy, G., Brett, S.J., 2018, Jan. Impossible decision? An investigation of risk trade-offs in the intensive care unit. Ergonomics 61 (1), 122-133. https://doi. org/10.1080/00140139.2017.1301573.

Rogers, A.E., Hwang, W.-T., Scott, L.D., 2004. The effects of work breaks on staff nurse performance. J. Nurs. Adm. 34 (11).

Sinnott, C., Moxey, J.M., Marjanovic, S., Leach, B., Hocking, L., Ball, S., Georgiadis, A., Lamé, G., Willars, J., Dixon-Woods, M., 2022. Identifying how GPs spend their time and the obstacles they face: a mixed-methods study. Br. J. Gen. Pract. BJGP 72 (715), e148-e160. https://doi.org/10.3399/bjgp.2021.0357, 2021.0357.

Slovic, P., Finucane, M.L., Peters, E., MacGregor, D.G., 2004. Risk as analysis and risk as feelings: some thoughts about affect, reason, risk, and rationality. Risk Anal. 24 (2). Nov. 2, 2004.

Stefancyk, A., 2009. One-hour, off-unit meal breaks. AJNR 109 (1).

Sujan, M., Spurgeon, P., Cooke, M., 2015. The role of dynamic trade-offs in creating safety-a qualitative study of handover across care boundaries in emergency care. Reliab. Eng. Syst. Saf. 141, 54-62. https://doi.org/10.1016/j.ress.2015.03.006.

Tawfik, D.S., Scheid, A., Profit, J., Shanafelt, T., Trockel, M., Adair, K.C., Sexton, J.B., Ioannidis, J.P.A., 2019, Oct 15. Evidence relating health care provider burnout and quality of care: a systematic review and meta-analysis. Ann. Intern. Med. 171 (8), 555-567. https://doi.org/10.7326/M19-1152.

Thorpe, J., 2020, Feb 2. Tackling burnout: why is it important? Br. J. Hosp. Med. 81 (2), 1-4. https://doi.org/10.12968/hmed.2019.0349.

Vicente, K.J., Christoffersen, K., 2006. The WalkertonE. colioutbreak: a test of Rasmussen's framework for risk management in a dynamic society. Theor. Issues Ergon. Sci. 7 (2), 93-112. https://doi.org/10.1080/14639220500078153. 